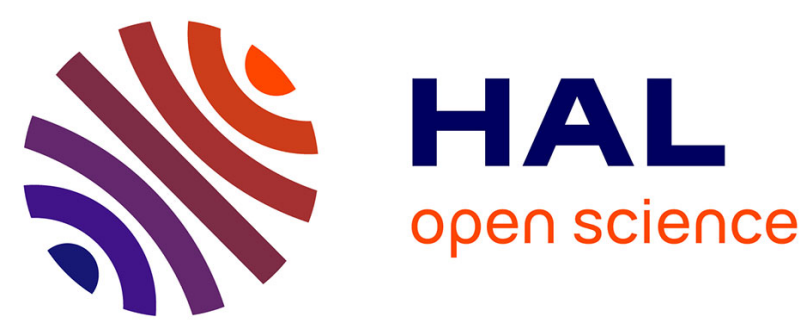

\title{
Perioperative use of gabapentinoids in France. Mismatch between clinical practice and scientific evidence
}

\author{
Valeria Martinez, Michel Carles, Emmanuel Marret, Hélène Beloeil
}

\section{To cite this version:}

Valeria Martinez, Michel Carles, Emmanuel Marret, Hélène Beloeil. Perioperative use of gabapentinoids in France. Mismatch between clinical practice and scientific evidence. Anaesthesia Critical Care \& Pain Medicine, 2018, 37 (1), pp.43-47. 10.1016/j.accpm.2017.01.010 . hal-01709942

HAL Id: hal-01709942

https://hal-univ-rennes1.archives-ouvertes.fr/hal-01709942

Submitted on 16 May 2018

HAL is a multi-disciplinary open access archive for the deposit and dissemination of scientific research documents, whether they are published or not. The documents may come from teaching and research institutions in France or abroad, or from public or private research centers.
L'archive ouverte pluridisciplinaire HAL, est destinée au dépôt et à la diffusion de documents scientifiques de niveau recherche, publiés ou non, émanant des établissements d'enseignement et de recherche français ou étrangers, des laboratoires publics ou privés. 


\section{Perioperative use of gabapentinoids in France}

Mismatch between clinical practice and scientific evidence

Valéria Martinez ${ }^{\mathrm{a}, \mathrm{b}}$, Michel Carles $^{\mathrm{c}}$ Emmanuel Marret $^{\mathrm{d}}$, Hélène Beloeil ${ }^{\mathrm{e}}$ on behalf of the Regional Anaesthesia and Pain Committee of the French Society of Anaesthesiology and Intensive Care ${ }^{1}$

a Service d'anesthésie, Hôpital Raymond Poincaré, Garches, Assistance Publique Hôpitaux de Paris, F-92380 France

${ }^{b}$ Inserm, U-987, Hôpital Ambroise Paré, Centre d'Evaluation et de Traitement de la Douleur, F-92100 France; Université Versailles Saint-Quentin, F-78035 France.

c Pôle d'Anesthésie Réanimations, Hôpital Pasteur 2, Centre Hospitalier Universitaire, Université Nice Sophia-Antipolis (UNS)

${ }^{\mathrm{d}}$ American hospital of Paris, 92200 Neuilly-sur-Seine, Paris, France

e Pôle Anesthésie-Réanimation, CHU Rennes, Université Rennes 1, UMR 991, CIC 1414, F35033 Rennes

${ }^{1}$ Collaborators : F.Aubrun, J. Cabaton, A.Lassere, I. leBlanc, J. Lhermitte, O. Rontes, M. Olivier, P. Sitbon, P. Zetlaoui

\section{Corresponding author}

Valéria Martinez

Service d'Anesthésie

Hôpital Raymond Poincaré, Garches

Assistance Publique Hôpitaux de Paris

F-92380, Garches, France

Phone: 33147107622

Fax: 33147107623

E-mail: valeria.martinez@rpc.aphp.fr 


\section{Abstract}

Background: Gabapentinoids have governmental health agency approval for "chronic neuropathic pain." Over the last decade, however, the perioperative prescription of gabapentinoids has become more popular among anaesthesiologists due to their anxiolytic and antihyperalgesic proprieties, despite weak scientific evidence supporting the risk/benefit ratio for this indication.

Methods: Our aim was to extensively describe the use of perioperative gabapentinoids by French anaesthesiologists. An online questionnaire was sent to the French Society of Anaesthesiology members. The questionnaire, focusing on gabapentinoid prescriptions, included questions on demographic data, patient conditions and types of surgeries, mode of prescription, motives, and presumed side effects (dizziness, confusion, desaturation and visual disorders).

Results: 508 questionnaires were analysed, among which $70 \%$ reported gabapentinoid use. Twenty five per cent of prescribers stated using gabapentinoids in all types of surgeries, $30 \%$ in outpatient surgeries and $46 \%$ in combination with regional anaesthesia. In $66 \%$ of the cases, preoperative and postoperative prescriptions were combined. Sedation, dizziness and visual disturbance were expected side effects according to $68 \%, 45 \%$ and $20 \%$ of anaesthesiologists, respectively. Reported reasons in favour of gabapentinoid prescription were prevention of chronic pain (93\%), expected high postoperative acute pain, i.e. painful surgeries (91\%), a history of chronic pain (72\%), and patient opioid dependence (72\%).

Discussion: French Anaesthesiologists have recently included gabapentinoids in the multimodal management of postoperative pain but they are unaware of certain frequent 
side-effects. Moreover, their expectations about the prevention of chronic pain are not validated. Our survey is a call to moderate the systematic prescription of these drugs in the perioperative period.

Key words: pregabalin, gabapentin, postoperative pain, chronic pain prevention, survey 


\section{Introduction}

Gabapentin and pregabalin are antiepileptic molecules whose effectiveness for the treatment of neuropathic pain was empirically discovered in 1965. Presynaptic binding of gabapentinoids to the alpha-2-delta subunit of a voltage-dependent calcium channel decreases the release of excitatory neurotransmitters, including glutamate and substance $P$. By modulating the calcium-induced release of neurotransmitters from activated paintransmitting neurons, gabapentinoids may inhibit pain transmission and decrease the hyperexcitability of dorsal horn neurons induced by tissue damage. Thus, gabapentinoids act like antihyperalgesic drugs inhibiting central sensitization. Based on this pathophysiological mechanism, their perioperative use became widespread, and has been integrated in multimodal analgesic approaches. However, gabapentinoids received governmental health agency approval (Autorisation de Mise sur le Marché: or "AMM") for "chronic neuropathic pain," but their use for the management of postoperative pain is off-label.

Several systematic reviews have reported benefits associated with the perioperative use of gabapentinoids. It has clearly been shown that gabapentinoids reduce morphine consumption, pain intensity during the first 24 hours and the risk of nausea and vomiting [111]. The evidence also indicated that the efficacy of gabapentinoids was largely restricted to surgical procedures associated with pro-nociceptive mechanisms, such as spine surgery, arthroplasty and amputations [5, 12]. However, adverse effects are common and specific to this therapeutic drug class. Reported evidence indicates a two- to three-fold increase in sedation, $30 \%$ higher frequencies of dizziness and a three- to six-fold increase in visual disturbances $[1,2,13,14]$. Recent studies have also questioned the advantage of including 
gabapentinoids in multimodal analgesic approaches and the risk/benefit ratio associated with their use [15]. In volunteers, pregabalin potentiated respiratory depression due to remifentanil, and the combination of these two drugs had an adverse effect on cognition [16]. Indeed, positive effects involving the prevention of chronic pain are very controversial $[1,17-19]$. Hence, the true value of multimodal opioid-gabapentinoid regimens remains incompletely established [20, 21].

Altogether, this led the Pain Committee of the French Society of Anaesthesiology and Intensive Care (Comité Douleur - Société française d'anesthésie et de réanimation CD-Sfar) to undertake a survey whose goal was to describe the prescription of perioperative gabapentinoids by French anaesthesiologists and compare it with scientific evidence from the last five years.

\section{Methods}

The CD-SFAR designed and validated an online questionnaire to be filled via an internet link, and sent it to the 2900 members of the SFAR using their e-mail addresses in March 2015. The questionnaire was also available through the SFAR website from March to June in 2015. The questionnaire covered demographic data, patient conditions and type of surgeries, prescription modes and motives, and presumed side effects according to the anaesthesiologists themselves (Appendix). Each anaesthesiologist could fill out the questionnaire only once. A descriptive analysis was performed. Statistics were performed using excel®. For continuous variables, means (SD) are reported unless otherwise indicated and for categorical variables, the number of patients in each category and the corresponding percentage are given. Finally, literature from the last five years was extensively reviewed in order to confront French Anaesthesiologist practices with scientific evidence. 


\section{Results}

A total of 508 questionnaires were returned and analysed from among all SFAR members ( $n=2900)$. Regarding the main clinical activity of anaesthesiologists, $92 \%$ of the responders declared working in the operating room, $7 \%$ as intensivists and $1 \%$ as chronic pain specialists. Over half of the responders had a faculty position in a public hospital, a third worked in private practices and $12 \%$ were residents. Among responders, $70 \%(n=356)$ declared using gabapentinoids in the perioperative period. The following results focused on the 356 gabapentinoid prescribers.

\section{Prescribing practice (Table 1)}

Gabapentin was prescribed three times more than pregabalin. Gabapentinoids were frequently given both pre- and postoperatively (66\%). A single dose ranged from 100 to $300 \mathrm{mg}$ for pregabalin and from 300 to $600 \mathrm{mg}$ for gabapentin. Gabapentinoids were mostly prescribed in adults, with paediatric use indicated in only $5 \%$ of responses. Doses are reduced in case of renal impairment and in the elderly (61\% and $80 \%$, respectively). Reported reasons in favour of gabapentinoid prescription were the prevention of chronic pain (93\%), expected high postoperative acute pain, i.e. painful surgeries (91\%), a history of chronic pain (72\%), and patient opioid dependence (72\%). Regarding the type of surgery, $25 \%$ of respondents stated that they used gabapentinoids in all types of surgery, $30 \%$ for cases of ambulatory surgery and $42 \%$ in association with loco regional anaesthesia. Gabapentinoids were frequently associated with other drugs either preoperatively $(31 \%$ of respondents associated another premedication) or intraoperatively (ketamine in $88 \%$ of 
cases). Dose adjustments were proposed in $80 \%$ of elderly and in $61 \%$ of renal dysfunction cases, respectively.

The vast majority of respondents $(76 \%)$ declared not being aware of the SFAR pain management guidelines regarding gabapentinoids. We noticed a difference depending on the main clinical activity declared: $74 \%(206 / 277)$ of anaesthesiologists and $95 \%(21 / 22)$ of intensivists were unaware of these guidelines $(p<0.01)$. None of the 7 respondents who declared having a chronic pain activity answered this question.

\section{Reasons for gabapentinoid prescription and expected side effects (Fig. 1 \& 2)}

Anaesthesiologist expectations concerning the benefits of gabapentinoids are high. They prescribe gabapentinoids because they expect an anxiolytic effect (58\%), an antihyperalgesic effect ( $89 \%$ ) associated with pain reduction as well as lower morphine requirements ( $87 \%$ ) and the prevention of neuropathic chronic pain (82\%). Seventy percent of responders believed that the perioperative use of gabapentinoids reduces by up to $30 \%$ the incidence of postoperative chronic neuropathic pain.

Regarding the statement about the expected side effects of gabapentinoids, sedation is the most frequently cited (68\%), followed by confusion and dizziness ( $45 \%)$, prolonged stay in the recovery room (24\%) and visual disturbances (20\%).

\section{Discussion}

To our knowledge, this is the first study reporting medical practices concerning the use of gabapentinoids since these molecules were proposed for postoperative pain management. Despite the inherent limits, the main result of this survey is that gabapentinoids are now part of routine prescriptions. When compared with the previous French survey in 2008, which reported no use of gabapentinoids in the perioperative period [22], practices have 
drastically changed. Seventy percent of the respondents declared prescribing gabapentinoids. However, for the vast majority of them (76\%), prescription was not systematic. They rather chose to adapt their prescription depending on the type of patient, the type of surgery and the benefit they were expecting from the molecule. The interest for gabapentinoids in major surgery and in the reduction of morphine use seems to be well understood among anaesthesiologists.

\section{Misunderstandings}

Certain responses pointed out misunderstandings about the efficacy of gabapentinoids for pain control.

Acute pain: A quarter of respondents use gabapentinoids in all types of surgery (whatever the expected postoperative pain) and even more used them in ambulatory surgeries. In contrast, a growing body of evidence has demonstrated that effectiveness is largely restricted to surgical procedures associated with pro-nociceptive mechanisms, such as spine surgery, joint arthroplasty and amputations $[5,12]$. Gabapentinoids and more specifically pregabalin, have not shown any pain control properties in minor surgeries, or head and neck and plastic surgeries [5, 12]. Thus, unlike current use, gabapentinoid prescription is inappropriate for pain control in minor surgeries. Our survey reported that gabapentinoids are largely prescribed in association with locoregional anaesthesia. Recent works also questioned the benefit of adding gabapentinoids to multimodal analgesic approaches and the risk/benefit ratio for their use. Indeed, the addition of gabapentin to a multimodal analgesic treatment combining intra-articular infiltration with non-opioid analgesics after knee replacement appeared both inefficient for pain control and morphine use and increased problematic side effects such as sedation, dizziness and severe adverse events [15]. 
Chronic pain: Almost all respondents prescribe gabapentinoids in surgeries at risk of chronic pain, because they believe that gabapentinoids prevent chronic pain, or prevent neuropathic pain. Surprisingly, published data are inconsistent; three previous metaanalyses evaluating prevention via gabapentinoids have reported conflicting results $[1,18$, 23]. A first meta-analysis published in 2012 supported the view that the perioperative use of pregabalin is effective in reducing the incidence of chronic postsurgical pain [18]. One year later, a Cochrane systematic review, including two new more trials, formulated contradicting conclusions [17]. In 2014, a pooled analysis of 6 trials concluded that the data necessary for drawing conclusions regarding chronic post-surgical pain (CPSP) are lacking [1]. Finally, the last systematic review, including $60 \%$ of unpublished trials, strongly increases the amount of evidence and enabled more confident conclusions. It indicated that pregabalin has no impact on the incidence of CPSP, regardless of the type of surgery, the dose and the timing of pregabalin administration [19].

\section{Lack of knowledge on side effects}

Our survey highlights that clinicians are not familiar with gabapentinoid-related side effects: few clinicians are aware of the risk of dizziness or visual disturbances, which are usual side effects associated with gabapentinoids, whereas they mainly expect a sedative effect. However, those "unfamiliar" adverse effects (e.g. dizziness or visual disturbances) are frequent and specific to this medication class. Previous systematic reviews reported a 2 to 3 fold increase in sedation, an increase in dizziness by one third and a 3 to 6 fold increase in visual disturbances when using gabapentinoids $[1,9,13,14]$. These side effects may compromise early rehabilitation [15], making the prescription of gabapentinoids in ambulatory surgery questionable. We did not questioned clinicians about the risk of 
potentiating opioid respiratory depression because this risk was unexpected by the members of the Pain Committee themselves. However, this severe side effect deserves more attention when taking into consideration recent publications, which point out that gabapentinoids do have this negative potential $[16,24]$. Indeed, case reports have noted that renal dysfunction, obstructive sleep apnoea and advanced age are risk factors for respiratory depression when pregabalin is administered in the perioperative period [25]. Our results showed that $61 \%$ and $80 \%$ of the physicians adjusted doses in patients with renal dysfunction or with advanced age, respectively. The association of gabapentinoids with other premedications could also be an issue. Our survey reported that $33 \%$ of prescribers combine gabapentinoids with other sedative premedications. Indeed, the cumulative sedative effect of gabapentinoids and traditional premedications (i.e. benzodiazepines) could lead to profound sedation and respiratory depression [25]. Our survey also reported that $88 \%$ of prescribers combine gabapentinoids with ketamine, a practice not supported by any clinical evidence. To date, only one study assessed the combination of ketamine with pregabalin. It found no benefit in terms of morphine consumption, postoperative pain and secondary hyperalgesia reduction [26]. Thus, combinations of antihyperalgesic drugs should be avoided since no benefit has been demonstrated, whereas it may increase the incidende of side effects. A clinical case reported that gabapentin and ketamine may have contributed to prolonged central nervous system depression during post-operative recovery [27]. Considering the benefit/risk ratio, the recent French guidelines on postoperative pain published by the SFAR do not recommend the routine use of perioperative gabapentinoids $[28]$.

Limitation: A survey has intrinsic bias that cannot be denied. The possibility of a response bias exists, since those who responded may have been more likely to use gabapentinoids. 
Another bias is that surveys are inevitably declarative and they do not ensure that the answers reflect the way that anaesthesiologists would behave in everyday patient care. Indeed, a survey does not take into account either doctor-patient interactions or the environmental aspects involved in real life. Our results are focused on answers from prescribers only. We did not question the non-prescriber. Finally, the 356 respondents represent only about $5 \%$ of the total number of French anaesthesiologists.

\section{Conclusion}

Our results highlight certain inconsistencies between reported practices and validated data regarding gabapentinoids used for the management of postoperative pain. Our results are in line with current expert opinions, especially that expressed in "Was There Rush Too Soon to Judgment?" [21]. Our survey is a call to moderate the systematic prescription of these drugs in the perioperative period. Specific attention should be paid to minor and ambulatory surgeries for which gabapentinoids are clearly not beneficial and potentially harmful. 
Table 1: Prescribing habits among anaesthesiologists who declared using gabapentinoids (percentages as the ratio of the number of positive responses to the total number responses) - Not all questionnaires were completed; therefore, the denominator is less than 356 (the number of questionnaires answering "yes" for gabapentinoid use).

\begin{tabular}{|c|c|c|}
\hline Question & Responses & Response rates \\
\hline \multirow[t]{3}{*}{ Which molecule? } & Pregabalin: & 67/344 (19.5\%) \\
\hline & Gabapentin: & $198 / 344(58 \%)$ \\
\hline & Both: & $79 / 344(23 \%)$ \\
\hline \multirow[t]{3}{*}{ When? } & Preoperative: & $157 / 335(47 \%)$ \\
\hline & Postoperative: & $51 / 335(15.2 \%)$ \\
\hline & Both: & $220 / 335(66 \%)$ \\
\hline \multirow[t]{3}{*}{ Which doses? } & $\begin{array}{l}\text { Pregabalin < } 100 \mathrm{mg} \text { or } \\
\text { gabapentin < } 300 \mathrm{mg} \text { : }\end{array}$ & $115 / 289(39.8 \%)$ \\
\hline & $\begin{array}{l}\text { Pregabalin } 100-300 \mathrm{mg} \text { or } \\
\text { gabapentin } 300-600 \mathrm{mg} \text { : }\end{array}$ & $145 / 289(50.2 \%)$ \\
\hline & $\begin{array}{l}\text { Pregabalin > } 300 \mathrm{mg} \text { or } \\
\text { gabapentin > } 600 \mathrm{mg}:\end{array}$ & $29 / 289(10 \%)$ \\
\hline \multirow[t]{4}{*}{ For which patients? } & Adults: & $319 / 326(97 \%)$ \\
\hline & Children: & $12 / 240(5 \%)^{*}$ \\
\hline & Patient with chronic preoperative pain: & $261 / 326(72 \%)$ \\
\hline & Opioid dependent patients: & $235 / 326(72 \%)$ \\
\hline \multirow{3}{*}{$\begin{array}{l}\text { For which type of } \\
\text { anaesthesia? }\end{array}$} & GA: & $249 / 326(76 \%)$ \\
\hline & RA: & $137 / 326(42 \%)$ \\
\hline & $\mathrm{GA}+\mathrm{RA}:$ & $272 / 326(83 \%)$ \\
\hline \multirow[t]{6}{*}{ For which surgeries? } & All surgeries: & $77 / 324(24 \%)$ \\
\hline & Major surgeries: & $249 / 324(77 \%)$ \\
\hline & Duration $>2 \mathrm{~h}$ : & $176 / 324(54 \%)$ \\
\hline & Painful surgeries: & $294 / 324(91 \%)$ \\
\hline & Surgeries at risk of CPSP: & $304 / 324(93 \%)$ \\
\hline & Outpatient surgeries & $96 / 326(29 \%)$ \\
\hline \multirow[t]{3}{*}{ How? } & In association with ketamine: & $266 / 302(88 \%)$ \\
\hline & In association with other premedications: & $81 / 287(31 \%)$ \\
\hline & Dose adjustment in the elderly: & $233 / 289(80 \%)$ \\
\hline
\end{tabular}


Dose adjustment in patients with renal $177 / 289(61 \%)$ failure:

GA: general anaesthesia, RA: regional anaesthesia, CPSP: chronic postsurgical pain.

*Among anaesthesiologists who declared having a paediatric anaesthesiology practice. 
Figure 1: Reported reasons in favour of gabapentinoid prescriptions (percentages as the ratio of the number of positive responses to the number of total responses).

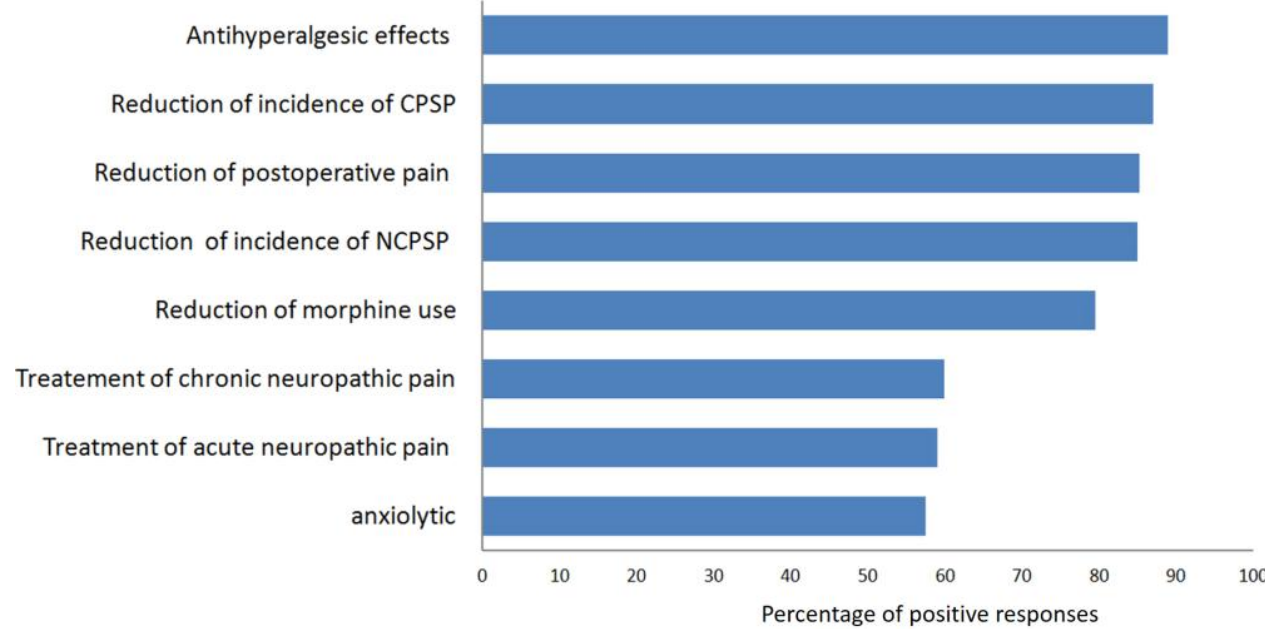

CPSP: chronic postsurgical pain; NCPSP: neuropathic postsurgical pain.

Comment [c1]: on the figure, change "anxiolytic" to "Anxiolytic" 
Figure 2: Expected side effects as reported in the questionnaire (percentages as the ratio of the number of positive responses to the number of total responses).

\section{prolongation of time in recovery room}

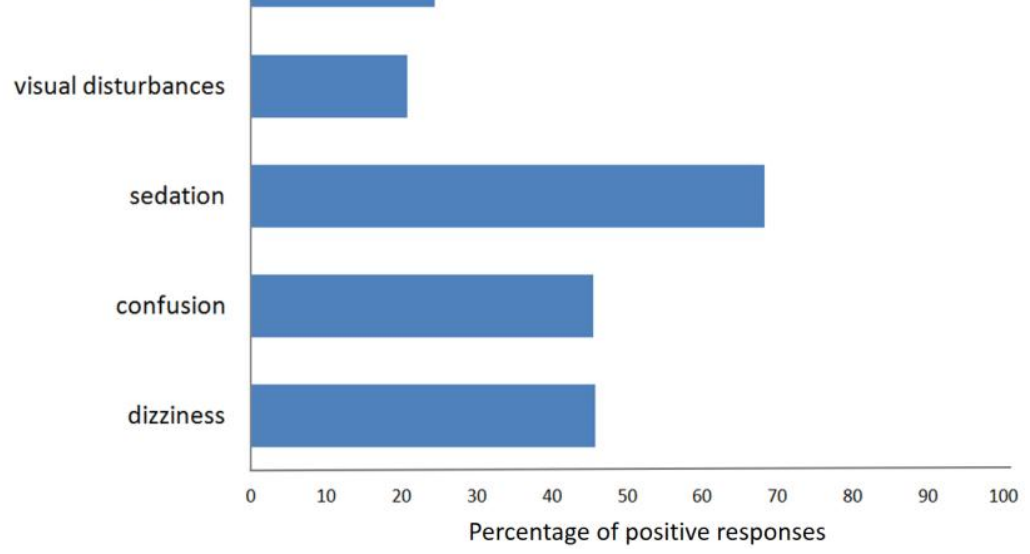

Comment [c2]: on the figure:

Prolongation of time in the recovery room

Visual disturbances

Sedation

Confusion 


\section{References}

1. Mishriky BM, Waldron NH, Habib AS. Impact of pregabalin on acute and persistent postoperative pain: a systematic review and meta-analysis. Br J Anaesth, 2015. 114:10-31.

2. Ho KY, Gan TJ, Habib AS. Gabapentin and postoperative pain--a systematic review of randomized controlled trials. Pain, 2006. 126:91-101.

3. Tiippana EM., et al., Do surgical patients benefit from perioperative gabapentin/pregabalin? A systematic review of efficacy and safety. Anesth Analg, 2007. 104: 1545-56.

4. Dahl JB, Mathiesen O, Moiniche S. 'Protective premedication': an option with gabapentin and related drugs? A review of gabapentin and pregabalin in in the treatment of post-operative pain. Acta Anaesthesiol Scand, 2004. 48;1130-6.

5. Eipe N, et al., Perioperative use of pregabalin for acute pain-a systematic review and meta-analysis. Pain, 2015. 156;1284-300.

6. Engelman E, Cateloy F. Efficacy and safety of perioperative pregabalin for post-operative pain: a metaanalysis of randomized-controlled trials. Acta Anaesthesiol Scand, 2011. 55;927-43.

7. Hurley RW, et al., The analgesic effects of perioperative gabapentin on postoperative pain: a metaanalysis. Reg Anesth Pain Med, 2006. 31;237-47.

8. Mathiesen O, Moiniche S, Dahl JB. Gabapentin and postoperative pain: a qualitative and quantitative systematic review, with focus on procedure. BMC Anesthesiol, 2007. 7: 6.

9. Seet E, et al., Effectiveness of 3-in-1 continuous femoral block of differing concentrations compared to patient controlled intravenous morphine for post total knee arthroplasty analgesia and knee rehabilitation. Anaesthesia and intensive care, 2006. 34:25-30.

10. Straube S, et al., Single dose oral gabapentin for established acute postoperative pain in adults Cochrane Database Syst Rev, 2010(5): p. CD008183.

11. Zhang J, Ho KY, Wang Y. Efficacy of pregabalin in acute postoperative pain: a meta-analysis. Br $\mathrm{J}$ Anaesth, 2011. 106:454-62.

12. Lam, D.M., et al., Efficacy of Pregabalin in Acute Postoperative Pain Under Different Surgical Categories: A Meta-Analysis. Medicine (Baltimore), 2015. 94: e1944.

13. Eipe, N., et al., The Perioperative Use of Pregabalin for Acute Pain- a Systematic Review and MetaAnalysis. Pain, 2015.

14. Remerand, F., et al., [Benefits and safety of perioperative pregabalin: a systematic review]. Ann $\mathrm{Fr}$ Anesth Reanim, 2011. 30:569-77.

15. Lunn TH, et al., Analgesic and sedative effects of perioperative gabapentin in total knee arthroplasty: a randomized, double-blind, placebo-controlled dose-finding study. Pain, 2015. 156:2438-48.

16. Myhre M, LM. Diep, and A. Stubhaug, Pregabalin Has Analgesic, Ventilatory, and Cognitive Effects in Combination with Remifentanil. Anesthesiology, 2016. 124:141-9.

17. Chaparro LE., et al., Pharmacotherapy for the prevention of chronic pain after surgery in adults. Cochrane Database Syst Rev, 2013(7): CD008307. 
18. Clarke $\mathrm{H}$, et al., The prevention of chronic postsurgical pain using gabapentin and pregabalin: a combined systematic review and meta-analysis. Anesth Analg, 2012. 115428-42.

19. Martinez V, X. Pichard, D. Fletcher, Perioperative pregabalin administration does not prevent chronic postoperative pain.Systematic review with a meta-analysis of randomized trials. pain 2017. in press.

20. Fletcher D, Martinez V. Should we use gabapentin for postoperative pain control? Pain, 2015. 156:2402-2403.

21. Kharasch ED, Eisenach JC. Wherefore Gabapentinoids?: Was There Rush Too Soon to Judgment? Anesthesiology, 2016. 124:10-2.

22. Fletcher D, et al., A patient-based national survey on postoperative pain management in France reveals significant achievements and persistent challenges. Pain, 2008. 137:441-51.

23. Chaparro LE, et al., Pharmacotherapy for the prevention of chronic pain after surgery in adults. Cochrane Database Syst Rev, 2013. (7)CD008307.

24. Weingarten TN, et al., Multimodal Analgesic Protocol and Postanesthesia Respiratory Depression During Phase I Recovery After Total Joint Arthroplasty. Reg Anesth Pain Med, 2015. 40:330-6.

25. Eipe N, Penning J. Postoperative respiratory depression with pregabalin: a case series and a preoperative decision algorithm. Pain Res Manag, 2011. 16:353-6.

26. Martinez V, et al., The analgesic efficiency of combined pregabalin and ketamine for total hip arthroplasty: A randomised, double-blind, controlled study. Anaesthesia, 2014. 69:46-52.

27. Elyassi AR, et al., Possible gabapentin and ketamine interaction causing prolonged central nervous system depression during post-operative recovery following cervical laminoplasty: a case report. J Med Case Rep, 2011. 5: 167.

28. http://sfar.org/reactualisation-de-la-recommandation-sur-la-douleur-postoperatoire/. 


\section{Appendix}

\section{SURVEY ON THE PERIOPERATIVE USE OF GABAPENTINOIDS}

\section{Your type of practice:}

Public non-teaching Hospital $\square \quad$ Public Teaching Hospital $\square \quad$ Private Hospital $\square$ Anaesthesiology $\square \quad$ Intensive Care $\square \quad$ Chronic Pain $\square$

Adults only $\square \quad$ Paediatrics only $\square \quad$ Adults and Paediatrics $\square$

Position: Staff $\square \quad$ Fellow $\square$ Professor $\square$ Private practitioner $\square$ Resident $\square$

Do you use gabapentinoids (pregabalin and / or gabapentin?) $\quad$ YES $\square$ NO $\square$

If NO: end of questionnaire

If YES:

1- Which gabapentinoids do you prescribe?

- Pregabalin "Lyrica"

- Gapapentin "Neurontin" $\square$

- Either $\square$

2- When do you prescribe gabapentinoids?

- Preoperatively only:

YES $\square$ NO $\square$

- Preoperatively and postoperatively: YES $\square$ NO $\square$

- Postoperatively only: YES $\square$ NO $\square$

3- In which situations are gabapentinoids indicated?

- As anxiolytics:

YES $\square$ NO $\square$

- To reduce morphing consumption:

YES $\square$ NO $\square$

- To reduce pain scores:

YES $\square$ NO $\square$

- For their anti-hyperalgesic effect:

YES $\square$ NO $\square$

- To reduce the incidence of chronic pain:

YES $\square$ NO $\square$

- To reduce the incidence of neuropathic pain: YES $\square$ NO $\square$

- To treat acute neuropathic pain:

YES $\square$ NO $\square$ 
- To treat chronic neuropathic pain:

YES $\square$ NO $\square$

\section{4- Type of patient}

- Adults:

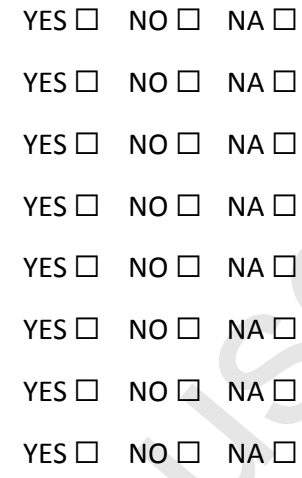

- Children

- Patient under general anaesthesia only:

- Patient under loco-regional anaesthesia only:

\section{5- Type of surgery}

- All surgeries:

- Long duration surgeries:

YES $\square \quad$ NO $\square \quad$ NA $\square$

- Major surgeries:

YES $\square \quad$ NO $\square \quad$ NA $\square$

YES $\square \quad$ NO $\square \quad$ NA $\square$

- Surgeries followed by severe postoperative pain:

YES $\square \quad$ NO $\square \quad$ NA $\square$

- Surgeries followed by chronic postoperative pain:

YES $\square \quad$ NO $\square \quad$ NA $\square$

\section{6- - Dosage and modalities of gabapentinoid administration:}

When do you prescribe the gabapentinoids?

- $\quad$ The day before surgery $\square$

- $\quad$ The day of surgery $\square$

- Both

Which doses do you prescribe?

- $\square$ pregabalin $\leq 100 \mathrm{mg}$ or gabapentin $\leq 600 \mathrm{mg}$ dose

- $\square$ between $100-300 \mathrm{mg}$ pregabalin or gabapentin between $600-900 \mathrm{mg}$ per dose

- $\square$ pregabalin > $300 \mathrm{mg}$ gabapentin or gabapentin > $900 \mathrm{mg}$ dose

Do you reduce the dose if:

- Renal impairment:

YES $\square$ NO $\square$

- In the elderly:

YES $\square$ NO $\square$ 
Do you prescribe other premedications (hydroxyzine, benzodiazepine) in addition to gabapentinoids? YES $\square$ NO $\square$

\section{7-Side Effects}

Which one of following side effects do you fear when using gabapentinoids?

- Dizziness:

YES $\square$ NO $\square$

- Confusion:

YES $\square$ NO $\square$

- Sedation:

YES $\square$ NO $\square$

- Visual disorders:

YES $\square$ NO $\square$

- Nausea or vomiting:

YES $\square$ NO $\square$

- Prolongation of recovery room stay:

YES $\square$ NO $\square$

\section{8- What do you think about gabapentinoids?}

According to you, the gabapentinoids can:

- Reduce morphine consumption at $24 \mathrm{~h}$

$\square$ No effect $\square$ less than $10 \mathrm{mg} \quad \square$ between $10-20 \mathrm{mg} \quad \square$ I do not know

- Decrease numerical pain scale scores at $24 \mathrm{~h}$

$\square$ No effect $\square$ between 1 - 3 points $\square$ more than 3 points $\square$ I do not know

- Decrease the incidence of nausea-vomiting
$\square$ No effect
$\square$ between 10 and $30 \%$
$\square$ more than $30 \%$
$\square$ I do not know

- Decrease the incidence of neuropathic pain

$\square$ No effect $\square$ between 10 and 30\% $\square$ more than 30\% $\square$ I do not know

- Decrease the incidence of sedation

$\square$ No effect $\square$ between 10 and 30\% $\square$ more than 30\% $\square$ I do not know

\section{Other}

- Do you use gabapentinoids in combination with ketamine?

YES $\square \quad$ NO $\square$

- Do you have institutional protocols for gabapentinoid administration?

YES $\square \quad$ NO $\square$

- Are you aware of the SFAR guidelines on the use of gabapapentinoids?

YES $\square \quad$ NO $\square$ 